This paper was accepted for publication in IEEE Transactions on Industrial Electronics in Aug 2015.

(C) 2015 IEEE. Personal use of this material is permitted. Permission from IEEE must be obtained for all other uses, in any current or future media, including reprinting/republishing this material for advertising or promotional purposes, creating new collective works, for resale or redistribution to servers or lists, or reuse of any copyrighted component of this work in other works. 


\title{
Winding Configurations for Five-Phase Synchronous Generators with Diode Rectifiers
}

\author{
S. Jordan, C.D. Manolopoulos and J. Apsley, Member, IEEE
}

\begin{abstract}
Wound field synchronous generators are widely used in aircraft and marine electrical systems. As the electric power requirements increase, there is renewed interest in dc power networks, but the electrical source remains a synchronous generator. The combination of a diode rectifier with a wound field multiphase generator reduces the voltage ripple on the dc network, and increases fault tolerance, compared with an equivalent 3-phase system. It also increases the options in terms of the winding design and configuration. This paper uses circuit modeling, including harmonics, informed by static finite element results, in order to understand the wound field generator performance for star and polygon connections of both short- and fully-pitched coils. Experimental results are used to validate the models. A polygon connection of short-pitched coils is shown to give good generator utilization for a healthy machine. However, careful design is required to prevent circulating harmonic currents. Under winding open-circuit faults, the polygon connection requires significant de-rating, making the star connection the preferred option.
\end{abstract}

Index Terms-DC network, aircraft electrical system, complex harmonic analysis, open-circuit fault.

\section{INTRODUCTION}

$\mathrm{T}$ HE wound field synchronous generator (WFSG) is a mature technology, that is used in aircraft, and marine applications [1]-[4] as well as land-based power systems [5] and many power quality standards are written around the properties of the WFSG [5]-[6]. Whilst utility networks are generally 3-phase ac, dc power systems are used in the majority of road vehicles as well as some aircraft and marine applications, with on-going debate about whether ac or dc is more appropriate [1]-[4]. In applications where the prime mover speed is determined by the propulsion needs, the advantages of dc networks are that the network frequency is

Manuscript received February 28, 2015; revised May 27, 2015 and July 31, 2015; accepted August 21, 2015.

Copyright (C) 2015 IEEE. Personal use of this material is permitted. However, permission to use this material for any other purposes must be obtained from the IEEE by sending a request to pubs-permissions@ieee.org.

This work was funded by the Engineering and Physical Sciences Research Council UK, Rolls-Royce plc and the Joseph Whitworth Trust.

S. Jordan was with the School of Electrical and Electronic Engineering, The University of Manchester, Manchester, M13 9PL, U.K. and is now with Newcastle University, (e-mail Steven.Jordan@newcastle.ac.uk).

C. Manolopoulos and J. Apsley are with the School of Electrical and Electronic Engineering, The University of Manchester, Manchester, M13 9PL, U.K. (e-mail: charalampos.manolopoulos@postgrad.manchester.ac.uk; j.apsley@manchester.ac.uk; phone: +44-161-3064732 ). not constrained by the speed of the prime mover [7], and that multiple generators can be connected without needing additional synchronization control [5]. The main disadvantage has been the lack of suitable dc protection systems, but this is changing with the increasing use of high voltage dc networks for long distance power transmission. Hence, dc networks are increasingly attractive for aircraft and marine applications [1][4]. However the electrical power source is often a 3-phase synchronous generator with one or more 6-pulse diode rectifier, to provide robust and cheap ac/dc conversion [3] that can be regulated by controlling the field current.

Many modern automotive applications use a permanent magnet (PM) generator, but this requires either a fully-rated converter or a separate $\mathrm{dc} / \mathrm{dc}$ stage to regulate the voltage. A hybrid PM and wound field generator combined with a diode rectifier is proposed by [8]-[9]; multiphase and concentrated winding designs are compared for higher specific torque, with reduced voltage ripple. In contrast, wound field synchronous machines have been optimised for fixed frequency, 3-phase, sinusoidal voltages with unbalanced loads [5], [10], and are often over-looked for high performance applications [11].

Multiphase induction machines have been shown to give improvements in torque density, better tolerance of opencircuit faults, cancellation of additional harmonics and reduced power rating per phase, compared with 3-phase machines [12]. Multiphase PM synchronous machines, for example [13]-[17], and synchronous reluctance machines [18] are in use, but few authors have considered WFSGs [19]. References [4] and [20] specifically consider the dual 3-phase topology, [21] is theoretical and [22] concentrates on the damper windings. Comparisons of experimental and simulation results are given in [23], but the focus is on dc voltage quality rather than generator current and torque ripple.

This paper investigates stator winding configurations for a conventional WFSG with a diode rectifier, considering fivephase windings, with fully-pitched (FP) or short-pitched (SP) coils connected in a star or polygon configuration as in [23]. Section II develops a fundamental symmetric-component analysis of the system to provide a broad understanding of how the stator winding configuration changes the generator behavior. Section III introduces the analytical modeling methods. These models are validated against experimental results for a reconfigurable $3 / 5 / 15$-phase $22 \mathrm{kVA}$ test machine, both for normal operation and under open-circuit fault conditions. Section VI compares winding configurations. 


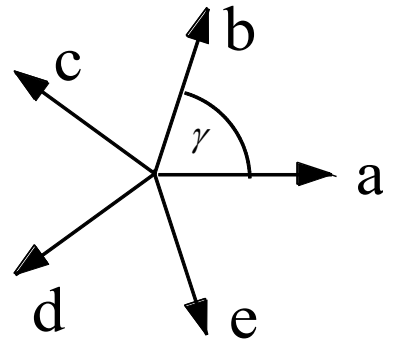

Fig. 1. Multiphase machine winding set.

\section{WINDING CONFIGURATION ANALYSIS}

\section{A. Inter-phase connections}

Multiphase machines are usually arranged either in multiple 3-phase sets, or as a balanced set [24]-[25]. This paper considers 5-phase machines only, where the windings are displaced by an angle of $\gamma=2 \pi / 5$ to form a balanced set, as shown in Figure 1.

For a rectified dc output, the $m$ phases may be connected through $m$ half-bridges, requiring 2 diodes per phase. Machine phases may be connected in star or polygon, as shown in Figure 2. The pentacle connection between non-adjacent phases [15], [26]-[27], was not considered in this study.

The difference between the star and polygon connections has been studied considering ideal sinusoidal voltage sources and a constant current load on the dc side [21], [28]. Assuming that the diodes turn on when there is a positive volts drop across them and turn off when the current reduces to zero, and neglecting the commutation time, then two diodes in the bridge will conduct at any time, with current commutating to the pair with the highest line-line voltage difference between them [29]. For a star-connected machine, the highest line-line voltage is the voltage difference between a pair of phases and current flows in only two phases at a time, as shown in Figure 2. However, for a polygon-connected machine, the voltage between terminals is the sum of the series-connected phase voltages between those terminals, and current flows through all windings, with two parallel paths, also shown in Figure 2. Consequently, [21] shows that for the two cases, phase voltage $\hat{V}_{a c}$ and peak dc voltage $\hat{V}_{d c}$ are related by:

$\hat{V}_{d c, \text { star }}=2 \hat{V}_{a c} \sin \frac{(m-1) \pi}{2 m}, \hat{V}_{d c, p o l y}=\hat{V}_{a c} \frac{1}{2 \sin (\pi / 2 m)}$
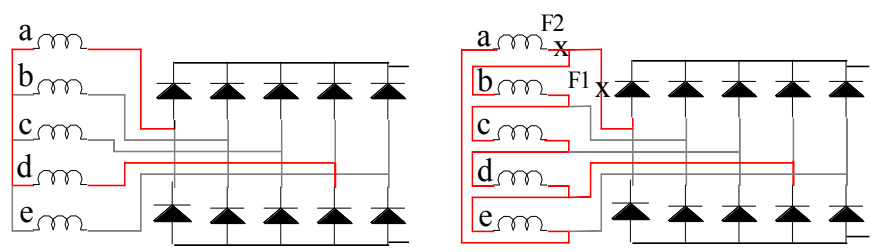

Fig. 2. Star (left) and polygon (right) winding connections.
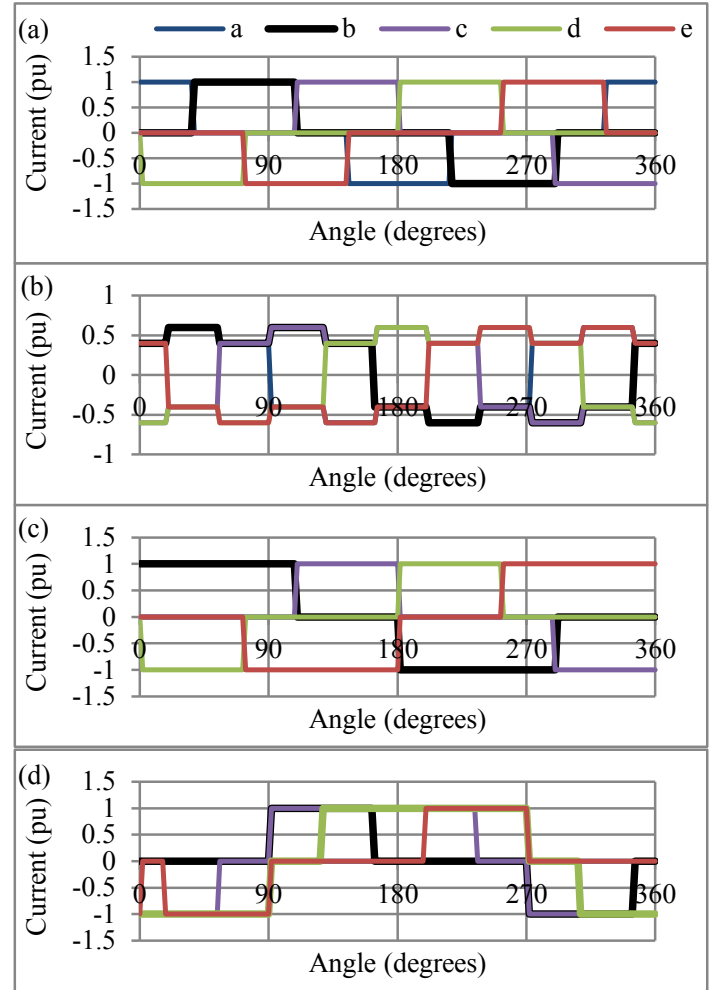

Fig. 3. Comparison of ideal current waveforms, (a) star, healthy, (b) polygon, healthy, (c) star, fault, (d) polygon, generator winding fault.

The ideal current waveforms also differ, as shown in Figures $3 \mathrm{a}$ and $3 \mathrm{~b}$ for a $1 \mathrm{pu}$ constant load current. The peak current in the polygon-connected machine is lower at $0.6 \mathrm{pu}$ rather than $1 \mathrm{pu}$ in the star-connected machine. Previous work has shown that the percentage DC voltage ripple is the same for both connections, but that the generator utilization is better for the polygon connection, because the form factor of the current is improved, reducing copper losses [21], [28].

\section{B. Open-circuit fault analysis}

In the case of a diode open-circuit fault, the pair of diodes with the next-highest voltage difference will conduct. This extends the conduction period for the adjacent diode, and generator winding, increasing their losses. For a star-connected generator, an open circuit in either the generator winding or diode leg results in the current waveforms shown in Figure 3c.

Most papers consider a line or diode fault [14], [16], [27]; in the polygon-connection this is location F1 in Figure 2. The conduction period for the adjacent diode is again extended, but the impact on the generator winding is reduced, since the current is shared between two conduction paths. However, if the open-circuit fault occurs in the generator winding, location F2 in Figure 2, then one of the parallel current paths is lost, significantly unbalancing its operation, as shown in Figure 3d. Since external line faults (F1) are already well covered in the literature, this paper exclusively addresses the internal machine fault (F2).

For the ideal currents shown in Figure 3, the current waveform can be expressed as a Fourier series expansion of 
the form:

$$
i(t)=\sqrt{2} \sum_{v=0}^{\infty} \sum_{i} D_{i} \frac{\sin \left(v \pi D_{i}\right)}{\left(v \pi D_{i}\right)} \cos \left[v\left(\theta-\theta_{i}\right)\right]
$$

where $v$ is the harmonic number, $D_{i}$ is the ratio of diode leg conduction time to the period of the waveform, with its ontime centered at angle $\theta_{i}$. The waveform in Figure $3 \mathrm{~b}$ can be expressed as the sum of a series of $i$ such pulses.

The method of symmetric components, [30] extended to multiphase by [31], represents the current distribution for an $m$-phase machine as a set of $m$ symmetric components:

$$
\left[\begin{array}{c}
i_{o} \\
i_{p} \\
i_{x} \\
i_{y} \\
i_{n}
\end{array}\right]=\sqrt{\frac{1}{m}}\left[\begin{array}{lllll}
a^{0} & a^{0} & a^{0} & a^{0} & a^{0} \\
a^{0} & a^{-1} & a^{-2} & a^{-3} & a^{-4} \\
a^{0} & a^{-2} & a^{-4} & a^{-6} & a^{-8} \\
a^{0} & a^{-3} & a^{-6} & a^{-9} & a^{-12} \\
a^{0} & a^{-4} & a^{-8} & a^{-12} & a^{-16}
\end{array}\right]\left[\begin{array}{c}
i_{a} \\
i_{b} \\
i_{c} \\
i_{d} \\
i_{e}
\end{array}\right]
$$

where $\alpha=e^{j \gamma}$.

For the ideal waveforms, values of the maximum fundamental phase current, $\left(\mathrm{I}_{1}\right)$, total phase current (I) and each symmetric component are given in Table I as rms values for a $1 \mathrm{pu}$ dc load current. Headings $\mathrm{p} \mathrm{n}$ and o denote positive, negative and zero sequence respectively and $\mathrm{x}$ and $\mathrm{y}$ identify the higher-order sequence set. Compared with the healthy generator, the star-connection shows $0.24 \mathrm{pu}$ negative sequence current during an open-circuit fault, an $8 \%$ reduction in positive sequence current, and a $22 \%$ increase in required current rating. In contrast, the polygon connection has no negative sequence component, but the zero sequence component equals the positive sequence value. There is no change in positive sequence current, but an $82 \%$ increase in required current rating. This suggests that if the generator can tolerate pulsating torques, the star-connection provides, better fault-tolerance, since it requires less de-rating. However if torque ripple is a problem, then the polygon connection is better.

\section{Winding pitch design}

Three-phase WFSGs are generally short-pitched to cancel the third harmonic and prevent circulating common-mode currents in delta-connected machines [10]. In a balanced multiphase machine, harmonic cancellation occurs between phases, reducing the net harmonic field in the airgap due to stator winding harmonics [12].

TABLE I

IDEAL GENERATOR CURRENTS FOR A HEALTHY MACHINE AND FAULTED MACHINE, WITH A 1PU DC LOAD CURRENT.

\begin{tabular}{lcccccccc}
\hline \hline \multicolumn{1}{c}{ Currents $(\mathrm{pu})$} & \multirow{2}{*}{$\mathrm{I}_{1} \max$} & $\mathrm{I} \max$ & \multicolumn{5}{c}{ I Symmetric } \\
\cline { 5 - 9 } & & & $\mathrm{p}$ & $\mathrm{x}$ & $\mathrm{y}$ & $\mathrm{n}$ & $\mathrm{o}$ \\
\hline Healthy star & 0.53 & 0.63 & 1.18 & 0.00 & 0.00 & 0.00 & 0.00 \\
\hline OC fault star & 0.73 & 0.77 & 1.09 & 0.38 & 0.47 & 0.24 & 0.00 \\
\hline Healthy poly. & 0.45 & 0.49 & 1.01 & 0.00 & 0.00 & 0.00 & 0.00 \\
\hline OC fault poly. & 0.86 & 0.89 & 1.01 & 0.00 & 0.00 & 0.00 & 1.01 \\
\hline \hline
\end{tabular}

TABLE II

HARMONIC WINDING FACTOR FOR DIFFERENT PITCH ANGLES.

\begin{tabular}{cccccccccc}
\hline $\begin{array}{l}\text { No. of } \\
\text { phases }\end{array}$ & $\begin{array}{c}\text { Pitch } \\
\text { angle }^{0}\end{array}$ & \multicolumn{7}{c}{ Harmonic number } \\
\hline & & 1 & 3 & 5 & 7 & 9 & 11 & 13 & 15 \\
\hline 5 & 180 & 0.99 & 0.87 & 0.67 & 0.40 & 0.13 & -0.11 & -0.28 & -0.33 \\
\hline 5 & 144 & 0.94 & 0.51 & 0.00 & -0.24 & -0.12 & 0.11 & 0.16 & 0.00 \\
\hline \hline
\end{tabular}

However, this also reduces the harmonic impedance at the stator terminals, which can give rise to high harmonic currents, if there are load-induced or rotor-field related harmonic voltages [32]. Since the harmonic cancellation is between phases, these harmonics are re-introduced during open-circuits faults. This paper therefore also considers the effect of shortpitching the winding for harmonic cancellation within a phase.

The winding function $k_{w}^{v}$ for the $v^{\text {th }}$ harmonic is given by [32],

$k_{w}^{v}=\frac{\sin (m v \beta / 2)}{(m v \beta / 2)} \sin (v \alpha / 2)$

where $v$ is the harmonic number, $\alpha$ is the winding pitch angle and $\beta$ is the slot angle. Table II lists the winding factor for the pitch angles used in the lab. These correspond to either full- or short-pitching by a number of slots to cancel the $m^{\text {th }}$ harmonic.

\section{MODELING METHODS}

The challenge of modeling a WFSG with a diode rectifier is in obtaining a sufficiently detailed model of the generator that is computationally efficient to run. Most authors either use a standard $5^{\text {th }}$ order d-q circuit model of the generator within a circuit simulation of the rectifier [4],[20],[21] or use timestepping finite element (FE) analysis combined with a circuit solver for the rectifier [33]-[34]. The transfer function approach in [35]-[36], may be useful for the dc network studies, but is not detailed enough for the generator configuration trade-offs. Whilst FE gives the most accurate method of determining generator performance, it requires detailed design data, takes a long time to run and does not give insight into the harmonic content of currents and torque. An intermediate approach is to use static FE solutions as look-up tables to inform the circuit model [34]. In this paper, a full complex harmonic model for a multiphase machine is derived, and then simplified in order to identify the inherent assumptions. Static FE was used to characterize the opencircuit back-emf harmonics.

The generator model is combined with a SimPowerSystems circuit model of the diode rectifier. Open-circuit faults are approximated as high impedances in the open-circuit path, as shown in Figure 4 for the polygon connection. The fault modelling is validated against practical results.

In a machine with a salient rotor, the rotor is shaped such that the airgap, $g$, is assumed to vary with rotor angle [10].

$1 / g=\left(1 / g_{0}\right)\left(1+\delta \cos 2 \theta_{r}\right)$

where $g_{0}$ is the average airgap distance and $\delta$ is the saliency ratio. 


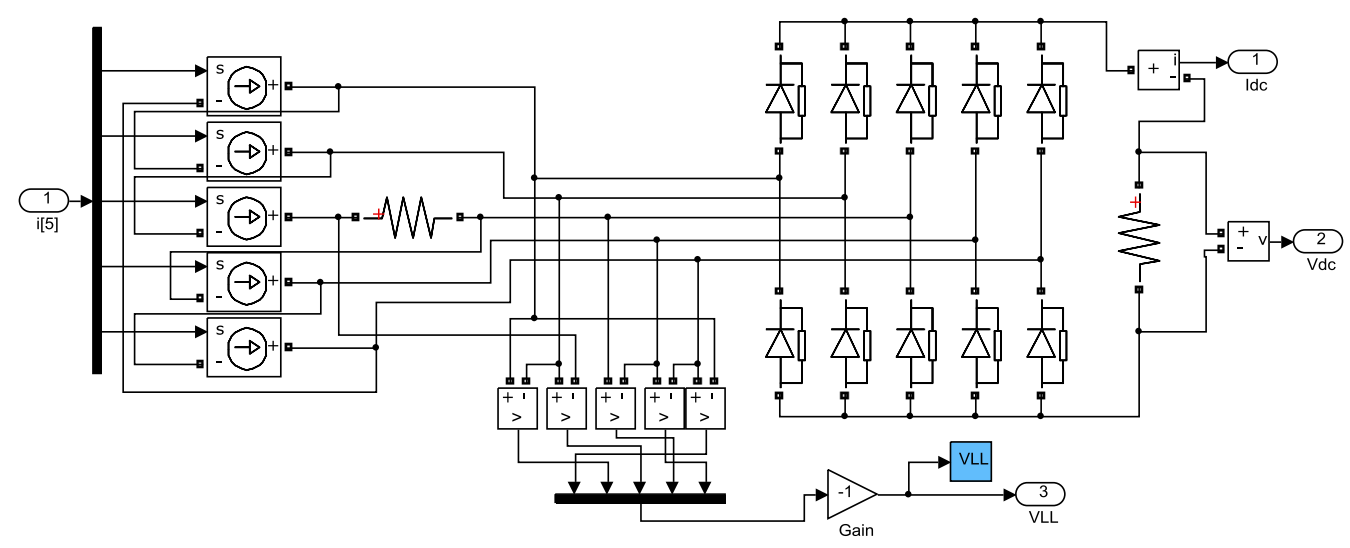

Fig. 4. Rectifier circuit for the polygon connection with an open circuit winding fault in phase c.

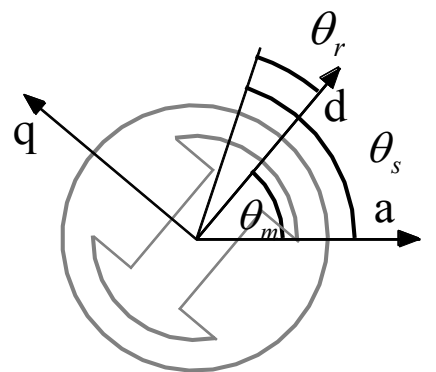

Fig. 5. Definition of winding axes and angles.

$\theta_{r}$ is the angle measured with respect to the rotor d-axis and relates to the angle with respect to the stator $\theta_{s}$ and mechanical angular position $\theta_{m}$ as shown in Figure 5 and (6).

$\theta_{r}=\theta_{s}-\theta_{m}$

Because of the rotor saliency, although the stator current distribution is identical to that for an induction machine, the magnetic couplings between stator windings and between stator and rotor depend on the rotor position.

$\boldsymbol{\psi}=\mathbf{L}_{a b c}\left(\theta_{r}\right) \mathbf{i}$

The full complex harmonic analysis (CHA) form of this equation is given in the appendix. A reduced form can be obtained, assuming ideal sinusoidal windings, where the harmonic number $v= \pm 1$. If the damper windings are combined into single $\mathrm{d}$ and $\mathrm{q}$ terms [34] the full harmonic model reduces to the fundamental equation form used by [4]. This can be transformed to an equivalent 2-phase set, together with $(m-3) / 2$ higher-order $\mathrm{d}-\mathrm{q}$ pairs and a zero sequence term using the extended Clarke's transformation [31].

If products of a fundamental and higher harmonic are included, but products of two harmonic components or a harmonic component and the saliency factor are neglected, then additional harmonic voltages are induced in the stator, (the $\omega_{m} \mathbf{G}_{c h a} \mathbf{i}_{c h a}$ terms in (23)). These terms were added to the 5 -phase fundamental model as a set of $v$ harmonic voltage sources $e_{v, k}$ of magnitude $E_{v}$ and phase $\varphi_{v}$, where $k$ is the phase a to e, to allow modeling of the circulating harmonic currents in the polygon connected machine, a technique widely used for PM machines. The $3^{\text {rd }}$ to $15^{\text {th }}$ odd harmonics were included, as derived from a static FE solution for open-circuit back-emf at rated armature voltage

$e_{v, k}=E_{v} \cos v\left(\theta+\varphi_{v}+(k-1) \gamma\right)$

Applying the Park's transformation to the fundamental phase set gives the usual form of the WFSG in the synchronous reference frame [10], where the equations have no dependence on rotor angle.

$\boldsymbol{\psi}_{d q}=\mathbf{L}_{d q} \mathbf{i}_{d q}$

$\mathbf{v}_{d q}=\mathbf{R}_{d q} \mathbf{i}_{d q}+\mathbf{L}_{d q} \frac{d \mathbf{i}_{d q}}{d t}+\omega_{m} \mathbf{G}_{d q} \mathbf{i}_{d q}+\mathbf{e}_{v, d q}$

$T_{e}=\mathbf{i}_{d q}{ }^{T} \mathbf{G}_{d q} \mathbf{i}_{d q}$

Where $\omega_{m}$ is the rotor angular frequency and $T_{e}$ is torque. $\psi$ is the flux linkage, $\mathbf{v}$ is the voltage, $\mathbf{i}$ is the current, in vector form, and $\mathbf{R}, \mathbf{L}$ and $\mathbf{G}$ are resistance and inductance matrices as defined below.

$\mathbf{v}_{d q}=\left[\begin{array}{lllll}v_{d} & v_{q} & v_{k d} & v_{k q} & v_{f}\end{array}\right]^{T}$

$\mathbf{i}_{d q}=\left[\begin{array}{lllll}i_{d} & i_{q} & i_{k d} & i_{k q} & i_{f}\end{array}\right]^{T}$

$\mathbf{L}_{d q}=\left[\begin{array}{ccccc}L_{d} & 0 & L_{m d} & 0 & L_{m d} \\ 0 & L_{q} & 0 & L_{m q} & 0 \\ L_{m d} & 0 & L_{k d} & 0 & L_{m d} \\ 0 & L_{m q} & 0 & L_{k q} & 0 \\ L_{m d} & 0 & L_{m d} & 0 & L_{f}\end{array}\right]$

$\mathbf{G}_{d q}=\left[\begin{array}{ccccc}0 & -L_{q} & 0 & -L_{m q} & 0 \\ L_{d} & 0 & L_{m d} & 0 & L_{m d} \\ 0 & 0 & 0 & 0 & 0 \\ 0 & 0 & 0 & 0 & 0 \\ 0 & 0 & 0 & 0 & 0\end{array}\right]$ 


$$
\mathbf{R}_{d q}=\left[\begin{array}{ccccc}
R_{s} & 0 & 0 & 0 & 0 \\
0 & R_{s} & 0 & 0 & 0 \\
0 & 0 & R_{k d} & 0 & 0 \\
0 & 0 & 0 & R_{k q} & 0 \\
0 & 0 & 0 & 0 & R_{f}
\end{array}\right]
$$

Subscripts are $d$ and $q$ for the two axis system (where the $d$ and $a$ phase axes are instantaneously aligned, for the case where the rotor angle is zero, and $q$ leads $d$ by $90^{\circ}$ ), $s$ indicates stator windings, $k$ indicates the damper windings and $f$ the field winding, and $m$ is a magnetizing component. The constant power form of the extended Clarke's transformation has been used in this analysis.

Higher order phase sets, denoted by the 0 subscript, are not coupled to the rotor, and currents are calculated in the stationary reference frame using

$$
v_{0}=R_{s} i_{0}+L_{l s} \frac{d i_{0}}{d t}
$$

\section{EXPERIMENTAL SYSTEM}

Results have been validated on a Cummins BCI162G generator. The machine was rewound as a set of fully-pitched 2-layer coils, to bring each end of each coil out to a cabinet where it could be configured as 3,5 or 15-phase, with star or polygon connections, to a standard bridge rectifier with a resistive load bank on the DC side [23]. The rewound machine is rated at $22 \mathrm{kVA}, 332 \mathrm{~V}, 50 \mathrm{~Hz}, 3000 \mathrm{rpm}$. No inductance or capacitance was used on the DC side. The effect of shortpitching was mimicked by shifting the second phase band with respect to the first, as shown in Table III. This gives the same winding factor as the true short-pitched case although end winding inductances are higher and there is a slight asymmetry in the a-phase leakage term.

The generator was driven from a DC machine, through a Ward-Leonard arrangement, with a RTW-300 Sensor Technology in-line torque transducer. Voltage and current measurements were recorded on a multi-channel LeCroy oscilloscope, with a $250 \mathrm{MHz}$ sampling, or logged through a dSpace system, together with torque and encoder speed measurements at a $10 \mathrm{kHz}$ sampling frequency [23]. Standard open-circuit, and slip tests were used to identify generator parameters. A locked rotor test was used to find damper terms [10], since the sub-transient time constant was shorter than one mains cycle. Parameter values are given in the Appendix.

TABLE III

WINDING LAYOUT FOR THE MACHINE, FULLY PITCHED (TOP) AND SHORTPITCHED (BOTTOM).

\begin{tabular}{lllllllllll}
\hline \hline Slots & $1-3$ & $4-6$ & $7-9$ & $10-12$ & $13-15$ & $16-18$ & $19-21$ & $22-24$ & $28-30$ & $28-30$
\end{tabular}

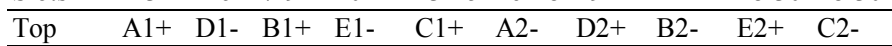

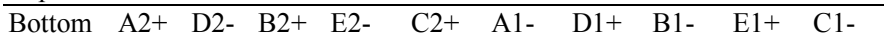

\begin{tabular}{lllllllllll}
\hline \hline Slots & $1-3$ & $4-6$ & $7-9$ & $10-12$ & $13-15$ & $16-18$ & $19-21$ & $22-24$ & $28-30$ & $28-30$
\end{tabular}

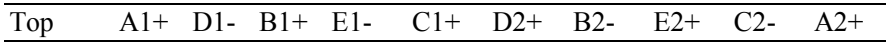

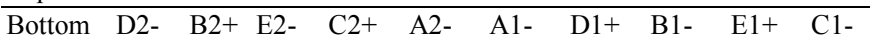

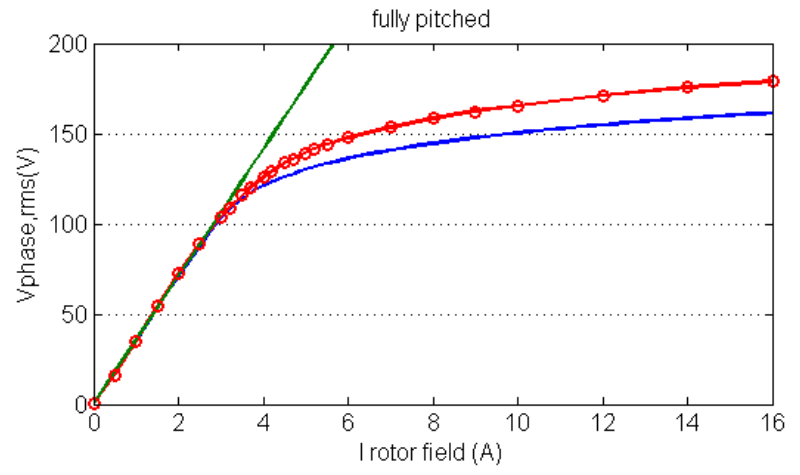

Fig. 6. Comparison of FE analysis (blue), measurements (red - circle) and the CHA model open circuit voltage at 2500rpm (green) for FP windings.

\section{EXPERIMENTAL RESULTS}

The aim of the experimental work was to validate the models used, over the limited test conditions available, in order to use the models to compare performance at equivalent load conditions.

Initial comparisons of open-circuit back-emf from the CHA model, the FE results, and experimental measurements, in Figure 6, show good agreement in the linear region. As expected, the linear CHA model does not model saturation, however the FE model also shows some discrepancy, probably due to incorrect material data.

A Fourier analysis of measured open-circuit voltage harmonics (Figure 7) shows significant variation with field current, especially for the FP winding, again indicating that a linear model will be unable to capture this detail. Similar analysis of the short-circuit current harmonics (not shown) also shows variations with field current. Figure 7 also shows FE results for rated field current, although results are closer to measured results for a low field current. Discrepancies may be due to numerical errors in the Fourier algorithm, which have accuracy of $\pm 0.5 \%$ of fundamental for all traces.

Figure 8 compares the reduced-form simulation with measured waveforms for ac side voltages and currents for a 5phase, healthy, polygon-connected generator, with a $15 \Omega$ resistive load. Measured results from 0 to $0.1 \mathrm{~s}$ are compared with the simulation from 0.1 to $0.2 \mathrm{~s}$. The SP generator currents in (a) are similar in shape to those in Figure 3, apart from some rounding due to the use of a resistive load, rather than a constant current load.

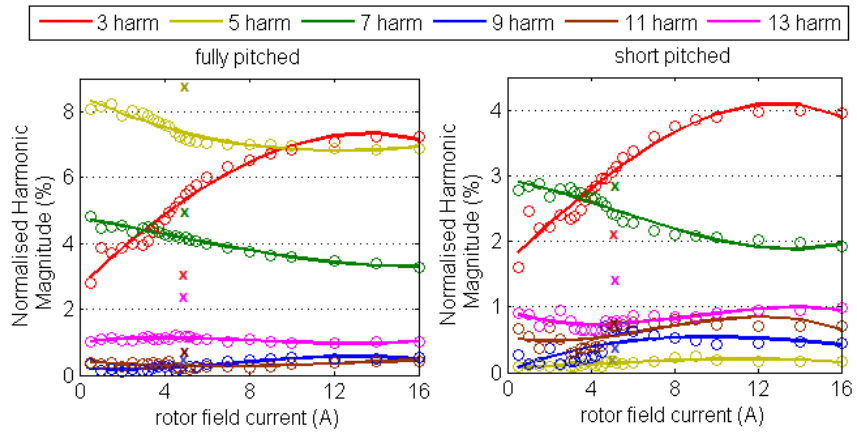

Fig. 7. Comparison of open circuit voltage harmonics for FP and SP windings as a function of field current. (o-measured, $x-F E$ ). 


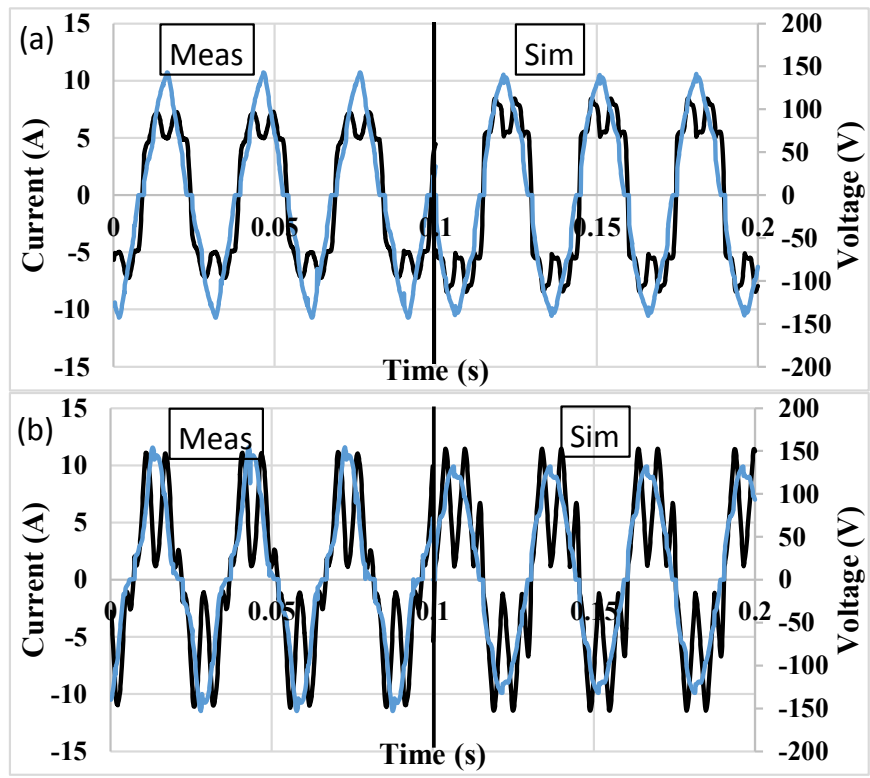

Fig. 8. SP (a) and FP (b) phase current (black) and phase voltage (blue), for the normal, polygon-connected generator at 2000rpm, $15 \Omega$, measured (left) and simulated (right).

However, the FP generator in (b) shows high levels of circulating $5^{\text {th }}$ harmonic zero-sequence currents, which are eliminated in the SP case.

Figure 9 compares currents in two phases of the open-circuit SP generator for (a) polygon and (b) star connections, with resistive loads of $15 \Omega$ and $20 \Omega$ respectively. Again, measured results from 0 to $0.1 \mathrm{~s}$ are compared with the simulation from 0.1 to $0.2 \mathrm{~s}$. In the star connection, the phase adjacent to the fault conducts for longer to compensate for the missing phase. In the polygon connection, the peak phase current has increased, compared with the healthy machine in Figure 8a, and the longer duration of current is in the non-adjacent phase. These effects are as expected from the ideal case in Figure 3. Similar results were obtained for the FP windings. In both Figures 8 and 9, there is a good match in waveform shapes between the measurements and simulation, although the simulation slightly overestimates the current.

Figure 10 compares measured and simulated generator torque for star and polygon connections of a FP generator in the normal (grey) condition and with an open-circuit winding (black), at $10 \mathrm{Nm}$ load, and 2000rpm. The traces confirm the analysis in Section II, showing high levels of second harmonic torque, corresponding to negative sequence generator currents in the star case, that are not present in the polygon connection.

The other main frequencies in the measured torque waveform correspond to the $2^{\text {nd }}$ harmonic of the slot-passing frequency [10], and $2 \%$ ripple torque at the fundamental frequency which is attributed to misalignment. The simulation over-estimates the torque, which is consistent with the overestimate of current, and also shows some $10^{\text {th }}$ harmonic, which is much attenuated in the measured torque. The dynamometer load acts as a two-inertia system, which filters the torque, with a calculated natural frequency of $87 \mathrm{~Hz}$ and a $40 \mathrm{~dB} /$ decade roll-off above this frequency.
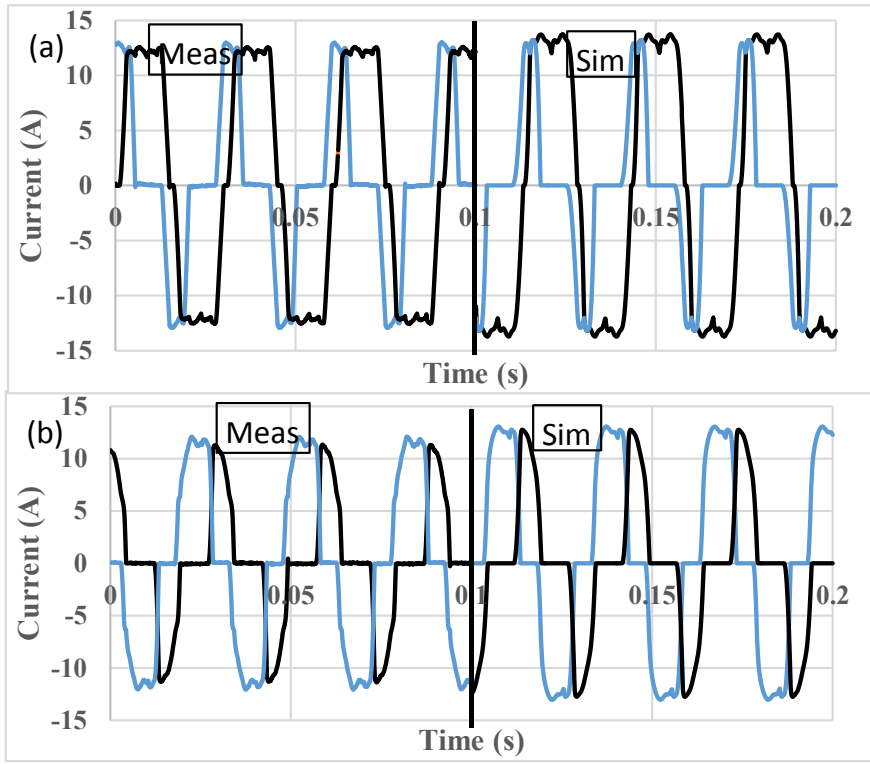

Fig. 9. Currents in the adjacent (blue) and non-adjacent (black) phase for an open-circuit fault in the SP generator at 2000rpm, simulated (left) and

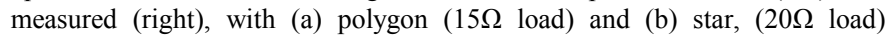
connections.
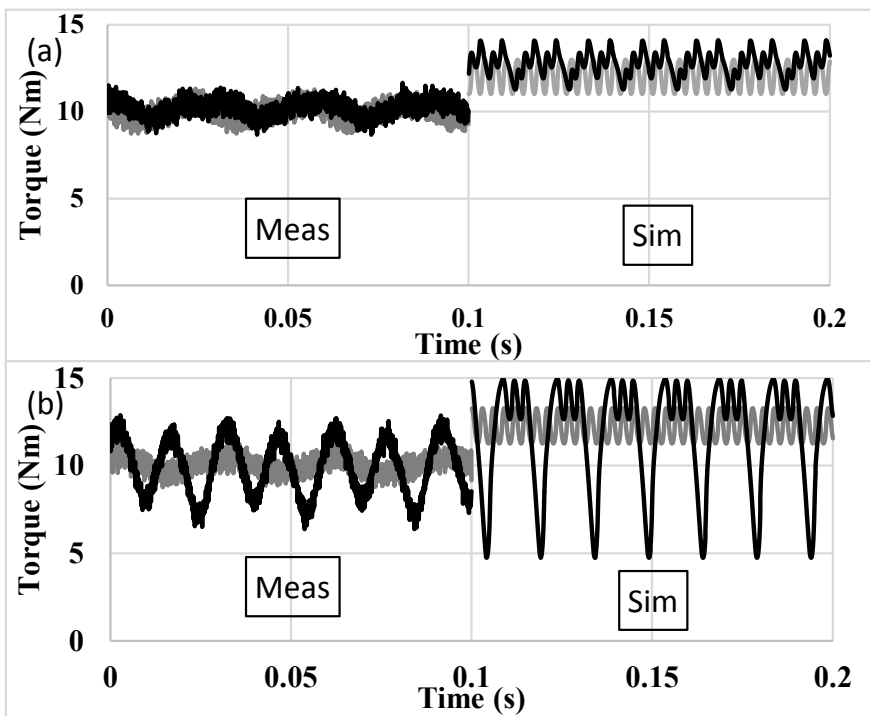

Fig. 10. Comparison of measured and simulated torque at 2000rpm, with a normal (grey) and open-circuit winding (black), for (a) polygon and (b) star connections, at $7 \%$ rated power.

\section{COMPARISON OF WINDING CONNECTIONS}

Table IV illustrates the trade-offs in choice of connection topology, based on experimental measurements for a 5-phase machine for comparable generator mechanical input power at 2000rpm. Measured results in Table IV show a worst-case increase in rms phase current of $31 \%$ and $68 \%$ (SP) and $39 \%$ and $64 \%$ (FP) for the star and polygon connections respectively, with an open-circuit fault and resistive load. Section II predicted increases in required current rating of $22 \%$ and $82 \%$ for a constant current load. The table confirms that significant $2^{\text {nd }}$ harmonic torque is present in the starconnected open-circuit fault case. 
TABLE IV

COMPARISON OF CONNECTIONS FOR THE 5-PHASE WINDING

\begin{tabular}{|c|c|c|c|c|c|c|c|}
\hline \multirow{3}{*}{ Connection } & \multicolumn{4}{|c|}{ Current } & \multicolumn{3}{|c|}{ Torque } \\
\hline & \multirow{2}{*}{$\begin{array}{c}\text { Average } \\
\text { A rms }\end{array}$} & \multirow{2}{*}{$\begin{array}{c}\text { Peak }^{1} \\
\%\end{array}$} & \multicolumn{2}{|c|}{$\operatorname{Max}^{1} \mathrm{rms} \%$} & \multirow{2}{*}{$\frac{\mathrm{dc}}{\mathrm{Nm}}$} & \multicolumn{2}{|c|}{$2^{\text {nd }}$ harm $^{2}$} \\
\hline & & & meas & $\operatorname{sim}$ & & meas & $\operatorname{sim}$ \\
\hline FP star & 6.40 & 183 & 103 & 100 & 10.1 & $0.8 \%$ & $0.3 \%$ \\
\hline FP poly & 6.21 & 182 & 102 & 100 & 10.0 & $1.0 \%$ & $0.3 \%$ \\
\hline FP star OC & 5.58 & 206 & 139 & 129 & 9.9 & $15.0 \%$ & $20.0 \%$ \\
\hline FP poly OC & 7.39 & 216 & 164 & 162 & 10.2 & $1.4 \%$ & $1.8 \%$ \\
\hline SP star & 6.40 & 173 & 104 & 100 & 10.1 & $0.6 \%$ & $0.3 \%$ \\
\hline SP poly & 6.16 & 146 & 100 & 100 & 9.8 & $0.9 \%$ & $0.3 \%$ \\
\hline SP star OC & 5.80 & 190 & 131 & 130 & 10.2 & $12.2 \%$ & $19.5 \%$ \\
\hline SP poly OC & 7.15 & 211 & 168 & 182 & 9.8 & $1.1 \%$ & $2.6 \%$ \\
\hline
\end{tabular}

Key: N-Normal, OC-Open circuit fault, Meas-Measured, Sim-Simulated.

${ }^{1}$ Percentage of average rms current in normal mode. ${ }^{2} \mathrm{rms}$ torque as a percentage of dc torque

The peak current is lower for the SP polygon than the star connection in normal operation, however, careful consideration of pitch factor is required. The FP polygon connection shows almost as high peak currents as the star connection. Under fault conditions, the polygon connection shows the most uneven distribution of currents with the highest maximum rms phase current.

\section{CONCLUSION}

This paper has compared winding configurations for a fivephase WFSG in normal operation and for open-circuit faults. Models have been developed and validated in order to compare the different winding configurations. The fundamental model alone was not able to predict circulating currents, but with the addition of voltage sources to represent the rotor-induced harmonics, which can be justified from the CHA analysis, it provides a computationally-efficient prediction of the rectifier currents. However, the linear models do not account for saturation, which requires either timestepping FE or use of pre-calculated look-up tables [37]-[38].

The polygon winding configuration is attractive for the SP winding in normal operation, in terms of lower peak currents in the generator, although currents in the rectifier are the same for both connection methods. The pitch factor must be carefully selected to prevent circulating low-order harmonic currents. However, as distinct from the open-circuit line case, studied by other researchers, in the case of an internal winding open-circuit fault, the user must choose between significant derating in a polygon-connected system, or higher torque and voltage ripple in the star-connected case.

Further work is required for better understanding of the purpose and operation of the damper windings for use with a diode rectifier system. For even sharing of currents and control of torque ripple, particularly during fault conditions an active rectifier would be required.
APPENDIX

A. Generator data

TABLE V

GENERATOR RATING AND PARAMETERS, STATOR REFERRED, FOR THE 5PHASE STAR-CONNECTED SP CONFIGURATION

\begin{tabular}{lcl}
\hline \hline \multicolumn{1}{c}{ Rating Data } & Parameters \\
\hline Power kVA $^{1}$ & 21.86 Stator resistance $\Omega$ & 0.259 \\
\hline Line-line voltage $\mathrm{V}^{1}$ & 199 d-damper resistance $\Omega$ & 0.133 \\
\hline Current A & 38.0 q-damper resistance $\Omega$ & 0.148 \\
\hline Poles & 2 Field resistance $\Omega$ & 0.260 \\
\hline Number of slots & 30 Stator leakage inductance $\mathrm{H}$ & 0.0017 \\
\hline Stator ID mm & 175 d-magnetizing inductance $\mathrm{H}$ & 0.0607 \\
\hline Min airgap mm & 1.2 q-magnetizing inductance $\mathrm{H}$ & 0.0297 \\
\hline Average airgap mm & 1.7 d-damper inductance $\mathrm{H}$ & 0.0599 \\
\hline Airgap variation $\delta$ & 0.68 q-damper inductance $\mathrm{H}$ & 0.0288 \\
\hline Active length mm & 137 Field inductance $\mathrm{H}$ & 0.0637 \\
\hline Stator turns $/$ coil & & \\
\hline \hline
\end{tabular}

${ }^{1}$ For the rewound machine with 7 turns/coil, (originally 8 ).

\section{B. Complex harmonic analysis}

In complex harmonic analysis, the turns distribution per unit stator angle $c_{c s}\left(\theta_{s}\right)$ is represented as a Fourier series expansion, where

$c_{c s}\left(\theta_{s}\right)=\sum_{v=-\infty}^{\infty} \bar{C}_{c s}^{v} e^{-j v \theta_{s}}$

$\bar{C}_{c s}^{v}=\frac{1}{2 \pi} \int_{-\pi} c_{c s}\left(\theta_{s}\right) e^{j v \theta_{s}} \cdot d \theta_{s}=-j N_{c s} e^{j v \theta_{0}} K_{p v} K_{b v}$

where $K_{p v}$ is the $v^{\text {th }}$ harmonic pitch factor, $K_{b v}$ is the $v^{\text {th }}$ harmonic slot mouth factor, $N_{c}$ is the number of turns and the coil axis is located at $\theta_{0}$ [39].

Summing over the set of series-connected coils in winding gives $c_{s 1}\left(\theta_{s}\right)$, with Fourier coefficient $\bar{C}_{s 1}^{v}$. The current density distribution $j_{s l}$ for current $i_{s l}$ is:

$j_{s 1}\left(\theta_{s}, t\right)=c_{s 1}\left(\theta_{s}\right) i_{s 1}(t)$.

The airgap variation, (5), can be expressed as a harmonic series, where $\delta_{\kappa}$ is the saliency ratio for the $\kappa^{\text {th }}$ harmonic.

$1 / g=\left(1 / g_{0}\right)\left(\sum_{\kappa=-\infty}^{\infty} \delta_{\kappa} e^{2 j \kappa \theta_{r}}\right)$

The magnetic flux density distribution $B_{s l}$, due to this current density distribution is given by [39], [18]:

$B_{s 1}=\frac{\mu_{0}}{g} \int j_{s 1} d \theta_{s}$
$B_{s 1}=-\frac{\mu_{0} i_{s 1}}{g_{0}} \sum_{\kappa=-\infty}^{\infty} \delta_{\kappa} \sum_{v=-\infty}^{\infty} \frac{\bar{C}_{s 1}^{v}}{j v} e^{j\left[2 \kappa\left(\theta_{s}-\theta_{m}\right)-v \theta_{1}\right]}$

The flux $\psi_{s 2 s I}$ due to current in winding 1, linking a second coil $c_{2}$ with a the coil axis located at $\theta_{2}$ is 
$\psi_{s 2 s 1}=w l \int_{0}^{2 \pi} c_{2}\left(\theta_{s}^{\prime}\right)\left[\int_{\theta_{s}^{\prime}} B_{s 1}\left(\theta_{s}\right) d \theta_{s}\right] d \theta_{s}^{\prime}$

Dividing the flux by the current in winding 1 gives the mutual inductance.

$L_{s 2 s 1}=L \sum_{\kappa=-\infty}^{\infty} \delta_{\kappa} \sum_{v=-\infty}^{\infty} \frac{\bar{C}_{s 1}^{v} \bar{C}_{s 2}^{2 \kappa-v}}{2 v(v-2 \kappa)} e^{-2 \kappa j \theta_{m}}$

where $L=-2 \pi \omega l \mu_{0} / g_{0}$, with $w$ as the mean airgap diameter and $l$ as the effective stack length of the machine.

Similar expressions can be written for the rotor, identified by the subscript $\mathrm{r}$.

$c_{r 1}\left(\theta_{r}\right)=\sum_{v=-\infty}^{\infty} \bar{C}_{r 1}^{v} e^{-j v \theta_{r}}$

The winding distribution with respect to the rotor can also be expressed in terms of stator angle and rotor angular position.

$c_{r 1}\left(\theta_{s}\right)=\sum_{v=-\infty}^{\infty} \bar{C}_{r 1}^{v} e^{-j v\left(\theta_{s}-\theta_{m}\right)}$

The same procedure as above gives:

$$
\begin{aligned}
& L_{r 2 s 1}=L \sum_{\kappa=-\infty}^{\infty} \delta_{k} \sum_{v=-\infty}^{\infty} \frac{\bar{C}_{s 1}^{v} \bar{C}_{r 2}^{2 \kappa-v}}{2 v(v-2 \kappa)} e^{-j v \theta_{m}} \\
& L_{s 2 r 1}=L \sum_{\kappa=-\infty}^{\infty} \delta_{\kappa} \sum_{v=-\infty}^{\infty} \frac{\bar{C}_{r 1}^{v} \bar{C}_{s 2}^{2 \kappa-v}}{2 v(v-2 \kappa)} e^{+j v \theta_{m}} \\
& L_{r 2 r 1}=L \sum_{k=-\infty}^{\infty} \delta_{\kappa} \sum_{v=-\infty}^{\infty} \frac{\bar{C}_{r 1}^{v} \bar{C}_{r 2}^{2 \kappa-v}}{2 v(v-2 \kappa)}
\end{aligned}
$$

Due to the symmetry of the machine, inductance is only non-zero for odd values of $v$, so the condition $v-2 \kappa=0$ does not arise. All variables are in their local reference frames and actual rather than stator-referred turns are used. As expected, there is no variation in rotor-rotor coupling with rotor position, and the form of expressions for rotor-stator and stator-rotor coupling are similar.

The full time-stepping model implements

$$
\mathbf{i}_{c h a}=\left[\mathbf{L}_{c h a}\right]^{-1} \int \mathbf{v}_{c h a}-\mathbf{R}_{c h a} \mathbf{i}_{\text {icha }}-\omega_{m} \mathbf{G}_{c h a} \mathbf{i}_{c h a}
$$

where there are $m$ stator phases, $n$ damper loops, denoted $k 1 \ldots k n$ and one field winding, so

$$
\begin{aligned}
& \mathbf{v}_{c h a}=\left[\begin{array}{llllllll}
v_{s a} & v_{s b} & \ldots & v_{s m} & v_{f} & v_{k 1} & \ldots & v_{k n}
\end{array}\right]^{T} \\
& \mathbf{i}_{c h a}=\left[\begin{array}{llllllll}
i_{s a} & i_{s b} & \ldots & i_{s m} & i_{f} & i_{k 1} & \ldots & i_{k n}
\end{array}\right]^{T} \\
& {\left[\begin{array}{ll|l}
\mathbf{L}_{c h a}
\end{array}\right]=\left[\begin{array}{lll}
\mathbf{L}_{s s m}\left(\theta_{m}\right)+L_{l s} & \sum_{v=-\infty}^{\infty} \mathbf{L}_{s r}\left(\theta_{m}, v\right) \\
\hline \sum_{v=-\infty}^{\infty} \mathbf{L}_{s r}\left(\theta_{m}, v\right) & \mathbf{L}_{r r m}+L_{l r}
\end{array}\right]}
\end{aligned}
$$

Mutual inductance terms are given by (19), (22) above, $L_{l r}$ and $L_{l r}$ denote stator and rotor leakage terms respectively, and
$\left[G_{c h a}\right]=\frac{\partial \mathbf{L}_{c h a}}{\partial \theta_{m}}$

The implementation pre-calculates the harmonic winding coefficients for each stator winding and the field winding and treats the damper bars as 8 individual loops [40]. Rotor angledependent terms are updated every time-step [39]. No account is taken of slotting effects, fringing, saturation or skew, since as indicated in the main text, the main purpose of this analysis was to understand the harmonic behaviour, rather than to improve the accuracy.

\section{ACKNOWLEDGMENT}

The authors would like to thank Cummins Generator Technologies for the donation of test equipment.

\section{REFERENCES}

[1] J.A. Rosero, J. A. Ortega, E. Aldabas, and L. A. R. L. Romeral, "Moving towards a more electric aircraft," IEEE Aerosp. Electron. Syst. Mag., vol. 22, no. 3, pp. 3-9, 2007.

[2] I. Moir and A. Seabridge, Aircraft Systems, $3^{\text {rd }}$ ed., John Wiley \&Sons Ltd., 2008.

[3] M. Weiming, "Development of vessel integrated power system." in Proc. IEEE ICEMS, Beijing, China, 2011

[4] M. Lin, A. K. Srivastava, and N. N. Schulz, "A generic digital model of multiphase synchronous generator for Shipboard Power System," in Proc. IEEE ESTS'07, Arlington, VA, USA, May 2007, pp. 348-355.

[5] P. Kundur, Power system stability and control, New York, McGrawhill, 1994.

[6] "Aircraft Electric Power Characteristics (MIL-STD-704F)," U.S. Dept. Defense, Washington, DC, USA, 2004.

[7] T. Feehally and J. Apsley. "The doubly-fed induction machine as an aero generator." In Proc. IEEE ECCE, Pittsburgh, PA, USA, Sept. 2014, pp. 1340-1347.

[8] N. Patin, L. Vido, E. Monmasson, J-P. Louis, M. Gabsi, and M. Lecrivain. "Control of a hybrid excitation synchronous generator for aircraft applications." IEEE Trans. Ind. Electron., vol. 55, no. 10, pp. 3772-3783, 2008.

[9] O. Beik, N. Schofield, and A. Al-Adsani. "Variable speed brushless hybrid permanent magnet generator for hybrid electric vehicles," in Proc. IEEE ITEC, Detroit, IL, USA, Jun 2014.

[10] I. Boldea, The Electrical Generators Handbook: Synchronous Generators, Boca Raton FL, CRC Press, 2006.

[11] D. G. Dorrell, "Are wound-rotor synchronous motors suitable for use in high efficiency torque-dense automotive drives?" In Proc. 38th IECON Montreal, QC, Canada, Oct. 2012, pp. 4880-4885.

[12] E. Levi, R. Bojoi, F. Profumo, H. A. Toliyat, and S. Williamson, "Multiphase induction motor drives-a technology status review," IET Electric Power Applications, vol. 1, no. 4, pp. 489-516, 2007.

[13] L. Parsa and H. A. Toliyat, "Five-phase permanent magnet motor drives for ship propulsion applications," in Proc. IEEE ESTS, Philadelphia, PA USA, July 2005, pp. 371-378.

[14] N. Bianchi, S. Bolognani, and M. Dai Pre, "Impact of stator winding of a five-phase permanent-magnet motor on post fault operations, " IEEE Trans. Ind. Electron., vol. 55, no. 5, pp. 1978-1987, 2008.

[15] S. Sadeghi, L. Guo, H. A. Toliyat, and L. Parsa. "Wide operational speed range of five-phase permanent magnet machines by using different stator winding configurations." IEEE Trans. Ind. Electron,. vol. 59, no. 6. pp. 2621-2631, 2012.

[16] N. E. A. M. Hassanain and J. E. Fletcher. "Steady-state performance assessment of three-and five-phase permanent magnet generators connected to a diode bridge rectifier under open-circuit faults," IET Renewable Power Generation, vol. 4, no. 5, pp 420-427, 2010. 
[17] N. Nguyen, F. Meinguet, E. Semail, and X. Kestelyn, "Fault-tolerant operation of an open-end winding five-phase PMSM drive with shortcircuit inverter fault," IEEE Trans. Ind. Electron., vol. PP, no. 99, pp. 11, 2015.

[18] H. A. Toliyat, S. P. Waikar, and T. A. Lipo. "Analysis and simulation of five-phase synchronous reluctance machines including third harmonic of airgap MMF." IEEE Trans. Ind. Appl., vol. 34, no. 2, pp. 332-339, 1998.

[19] M. Duran and F. Barrero, "Recent advances in the design, modeling and control of multiphase machines - Part 2", IEEE Trans. Ind. Electron., vol. PP, no.99, pp.1-10, 2015.

[20] S. D. Sudhoff. "Analysis and average-value modeling of dual linecommutated converter-6-phase synchronous machine systems." IEEE Trans. Energy Convers., vol. 8, no. 3, pp. 411-417, 1993.

[21] Y. V. Zozulin, "Calculation of currents and voltages for multiphase synchronous generators with bridge-rectifier load." Sov. Electr. Eng.(Engl. Transl.), vol. 51, no. 5, 1980.

[22] M. Mezzarobba, L. Spangaro, A. Tessarolo, "Experimental evaluation of damper circuit influence on the performance of multiphase synchronous generators feeding multiple rectifiers," in Proc. IEEE POWERENG, Torremolinos, Spain, May 2011.

[23] S. Jordan and J. Apsley. "Open-circuit fault analysis of diode rectified multiphase synchronous generators for DC aircraft power systems." in Proc. IEEE IEMDC, Chicago, IL, USA, May 2013 pp. 926-932.

[24] G. K. Singh, "Multi-phase induction machine drive research—a survey." Electric Power Systems Research, vol. 61, no. 2, pp139-147, 2002.

[25] E. A. Klingshirn, "High phase order induction motors-Part I-Description and theoretical considerations." IEEE Trans. Power App. Syst., vol. 1 pp. 47-53, 1983.

[26] A. S. Abdel-Khalik, A. S. Morsy, S. Ahmed, and A. M. Massoud. "Effect of stator winding connection on performance of five-phase induction machines," IEEE Trans. Ind. Electron., vol. 61, no. 1, pp. 319,2014

[27] A. S. Abdel-Khalik, M. A. Elgenedy, S. Ahmed, and A. M. Massoud, "An improved fault tolerant five-phase induction machine using a combined star/pentagon single layer stator winding connection", IEEE Trans. Ind. Electron., vol. PP, no. 99, pp. 11, 2015.

[28] S. Jordan and J. Apsley. "Diode rectification of multiphase synchronous generators for aircraft applications." in Proc. IEEE ECCE, Phoenix, AZ, USA, Sept. 2011, pp. 3208-3215.

[29] N. Mohan, T. Undeland, and W. Robbins, "Power electronics: converters applications and design", Wiley, 2002.

[30] C. L. Fortescue, "Method of symmetrical co-ordinates applied to the solution of polyphase networks." Trans. Amer. Inst. Elect. Engineers, vol. 37 , no. 2, pp. 1027-1140, 1918.

[31] D. C. White and H. H. Woodson, "Electromechanical Energy Conversion", New York, John Wiley and Sons Inc, 1959.

[32] A. E. Fitzgerald, C. Kingsley, Jr., and S. D. Umans, Electric Machinery, 6th ed., New York, McGraw-Hill, 2003.

[33] S. Williamson and A. F. Volschenk, "Time-stepping finite element analysis for a synchronous generator feeding a rectifier load," IEE Proc. Electric Power Applicat., vol. 142, no. 1, pp. 50-56, 1995.

[34] F. Deng and N. A. Demerdash "Comprehensive salient-pole synchronous machine parametric design analysis using time-step finite element-state space modeling techniques," IEEE Trans. Energy Convers., vol. 13, no. 3, pp. 221-229, 1998

[35] I. Jadric, D. Borojevic, and M. Jadric. "Modeling and control of a synchronous generator with an active DC load," IEEE Trans. Power Electron, vol. 15, no. 2, pp303-311, 2000.

[36] J. Sun, Z. Bing, and K. J. Karimi. "Input impedance modeling of multipulse rectifiers by harmonic linearization," IEEE Trans. Power Electron, vol. 24, no. 12, pp. 2812-2820, 2009.

[37] E. Levi, "Saturation modelling in dq axis models of salient pole synchronous machines," IEEE Trans. Energy Convers., vol. 14, no. 1, pp. 44-50, 1999.

[38] S-A. Tahan and I. Kamwa. "A two-factor saturation model for synchronous machines with multiple rotor circuits," IEEE Trans. Energy Convers., vol. 10, no. 4, pp. 609-616, 1995.
[39] D. S. Vilchis-Rodriguez, S. Djurovic, and A. C. Smith, "Wound rotor induction generator bearing fault modeling and detection using stator current analysis," IET Renewable Power Generation, vol. 7, no. 4, pp. 330-340, 2013.

[40] A. M. Knight, H. Karmaker, and K. Weeber. "Use of a permeance model to predict force harmonic components and damper winding effects in salient-pole synchronous machines," IEEE Trans. Energy Convers., vol. 17, no. 4, pp. 478-484, 2002.

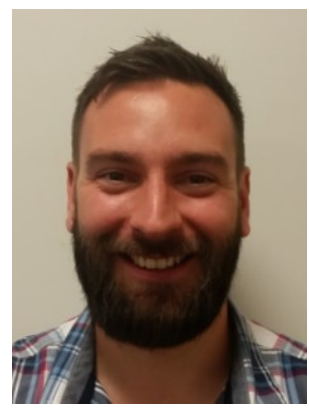

Steven Jordan received his M.Eng. and Ph.D. degrees from The University of Manchester, Manchester, U.K., in 2009 and 2013, respectively.

He qualified as an apprentice engineer with Jaguar Cars Ltd. before undertaking his further studies. He was elected Whitworth Scholar, and Whitworth Senior Scholar, on completion of his respective degrees. He is a Research Associate at Newcastle University, Newcastle, U.K., where his main research interests includes the design, simulation and finite element modeling of machines and drives for aerospace and vehicle applications.

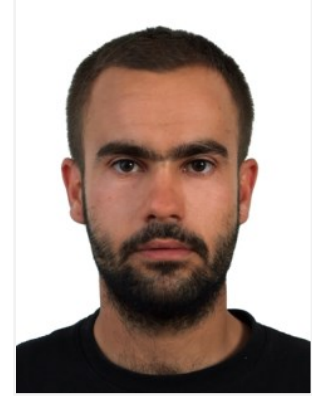

Charalampos D. Manolopoulos received the Diploma in Electrical and Computer Engineering from the Aristotle University of Thessaloniki, Greece, in 2011 and the MSc in Electrical Energy Conversion Systems from The University of Manchester, Manchester, U.K., in 2014.

In 2014-2015 he was a Research Assistant in The University of Manchester, Manchester, U.K. His research interests include modeling of electrical machines and power electronics.

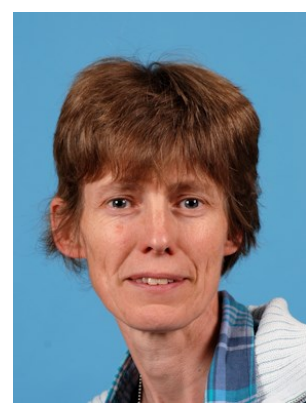

Judith M. Apsley (M '04) received the B.A. degree from the University of Cambridge, Cambridge, U.K., in 1986 and the Ph.D. degree from the University of Surrey, Surrey, U.K., in 1996.

She worked at Westland Helicopters, 19821987, ERA Technology, 1987-1995, and LSA Technology, 1996-2001, before joining The University of Manchester, Manchester, U.K., as a Research Associate, where she has been a Lecturer since 2008. Her main research interests are the modeling and control of electrical drive and generator systems for aircraft and marine applications. 